\title{
Hen egg white lysozyme is less active against Gardnerella vaginalis biofilm than human lysozyme
}

\author{
Olivier Thellin ${ }^{1 \star}$, Danièle Zorzi ${ }^{1}$, Pierrette Melin², Philippe Delvenne ${ }^{3}$, Ernst Heinen ${ }^{1}$, Willy \\ Zorzi $^{1}$, Benaïssa El Moualij ${ }^{1}$ and Pascale Quatresooz ${ }^{1}$ \\ ${ }^{1}$ Department of Human Histology-CRPP, University of Liège, Sart Tilman, Liège, Belgium. \\ ${ }^{2}$ Medical Microbiology, University Hospital of Liège, Liège, Belgium. \\ ${ }^{3}$ Laboratory of Experimental Pathology (LEP), GIGA-Cancer, University of Liège, Sart Tilman, Liège, Belgium.
}

Accepted 9 February, 2018

\begin{abstract}
Bacterial vaginosis is a condition that affects millions of women worldwide. In most cases, it can be linked to the presence of Gardnerella vaginalis. Classical metronidazole treatments can lead to recurrence of bacterial vaginosis in more than $50 \%$ of cases due to its inability to fully eradicate the infection. This can be due to protective shielding of $G$. vaginalis by the biofilm it synthesizes. We showed previously that the coadministration of recombinant human lysozyme, as a biofilm-degrading agent, with the antibiotic greatly improves its efficiency in vitro. Lysozyme purified from egg white is less expensive than recombinant human lysozyme and is commonly produced as an additive for human consumption. Our goal was to compare the effects of recombinant human lysozyme with that of egg white lysozyme alongside a conventional antibiotic treatment for bacterial vaginosis, using in vitro vaginal biofilm models. The results obtained here show that recombinant human lysozyme is a more efficient biofilm-degrading agent than egg white lysozyme and therefore constitutes a better choice as an anti-biofilm co-treatment for current vaginal antibiotherapy against $G$. vaginalis infection.
\end{abstract}

Keywords: Hen egg white lysozyme, recombinant human lysozyme, Gardnerella vaginalis, biofilm.

*Corresponding author. E-mail: o.thellin@uliege.be. Tel: +32-4-366.43.29. Fax: +32-4-366.43.21.

\section{INTRODUCTION}

Bacterial vaginosis (BV) is the most common vaginal infection worldwide (Muzny and Schwebke, 2016), with an estimation of approximately $30 \%$ of women affected (Livengood, 2009). Its prevalence varies between ethnic groups and, to a lesser extent, between geographical zones (Kenyon et al., 2013). BV results from vaginal dysbiosis characterized by a shift in commensal saprophytic vaginal microflora dominated by lactobacilli, to a microflora dominated by facultative and strict anaerobes (Hillier, 1993). While still poorly understood and categorized due to probable multifactorial origins (Reid, 2018), BV is linked in most cases to the presence of Gardnerella vaginalis (Schwebke et al., 2014; Hay, 2017), which can produce a biofilm that is not degraded by antibiotic treatment and that protects the bacteria against antibiotherapy (Thellin et al., 2016). One consequence is that numerous patients suffer from recurrent infections (Bradshaw et al., 2006; Sobel et al., 2006). This occurs not only because antibiotics can be trapped by the biofilm matrix components and are therefore unable to efficiently reach all bacteria embedded in the biofilm (Nichols et al., 1988), potentially leading to antibiotic resistance phenomena; but also because the remaining biofilm could provide a shelter for new pathogens (Fux et al., 2006), leading to new infections. Bacteria inside biofilms can also be in a quiescent state, evading antibiotic effects (Gilbert et al., 2002). We recently showed in vitro that the coadministration of an antibiotic and recombinant human lysozyme, acting as a biofilm-degrading agent, could succeed in both degrading a $G$. vaginalis biofilm and killing all the bacteria that were present inside that biofilm (Thellin et al., 2016). Egg white lysozyme is less expensive than recombinant human lysozyme and is 
already mass-produced for the food industry. Therefore, the aim of this article was to determine if egg white lysozyme or recombinant human lysozyme could be used as a co-treatment for antibiotherapies, and which would be more appropriate when administered in combination with antibiotics to treat vaginal pathological biofilms based on $G$. vaginalis.

\section{MATERIALS AND METHODS}

\section{Tested lysozymes}

Four commercial lysozymes (one recombinant human lysozyme and three hen egg white lysozymes) were selected as models in the present work. The recombinant human lysozyme was coded HS (Sigma Aldrich, catalog number L1667, Belgium). The three hen egg white lysozyme are purified from chicken egg white and were coded OS (Sigma Aldrich, catalog number L6876, Belgium), OMS (BNLfood, Lysozyme Hypochloride - standard grade, Belgium), and OMP (BNLfood, Lysozyme Hypochloride - pharmaceutical grade, Belgium).

\section{Toxicity test on eukaryotic cells (MTS Assay)}

The potential toxicity of each of the lysozymes was tested on the vk2/E6E7 cell line (Fichorova et al., 1997), representative of the vaginal epithelial cell. For this, 20,000 cells were placed in each well of a flat bottom culture plate in Keratinocyte-SFM medium with L-glutamine without $\mathrm{CaCl}_{2}$ (Life Technologies, Belgium) supplemented with final concentrations of epidermal growth factor $0.1 \mathrm{ng} / \mathrm{ml}$, bovine pituitary extract $50 \mu \mathrm{g} / \mathrm{ml}$, penicillin/streptomycin $1 \%$, and $\mathrm{CaCl}_{2} 0.4 \mathrm{mM}$. Each culture condition was performed in triplicate. After $24 \mathrm{~h}$, the cells reached $85 \%$ confluence. Lysozymes were added at the following concentrations, selected from previous work (Thellin et al., 2016): 500, 1,000, 2,000, 10,000, 20,000, $30,000,60,000$ and $100,000 \mathrm{U} / \mathrm{ml}$. Then, $20 \mu \mathrm{l}$ of CellTiter 96 AQueous One solution reagent (Promega Benelux, Belgium) was added after $24 \mathrm{~h}, 48 \mathrm{~h}$, or $72 \mathrm{~h}$, incubated for $1 \mathrm{~h}$ at $37^{\circ} \mathrm{C}$ then quantitated by optical density determination at $492 \mathrm{~nm}$ using an Epoch microplate spectrophotometer (BioTek Instruments, Winooski, VT, USA). For the 7-day incubation period, the culture medium was replaced after 4 days with fresh medium and lysozyme preparations.

\section{Biofilm quantification and bactericidal assay}

A clinical strain of $G$. vaginalis was isolated by the LMM (Laboratoire de Microbiologie Medicale, Prof. Pierrette Melin, CHU of Liege, Belgium) from a vaginal sample, identified as $G$. vaginalis using a Bruker Microflex LT MALDI-TOF (Matrix Assisted Laser Desorption Ionisation - Time Of Flight) mass spectrometer running the MALDI Biotyper 3.1 software. This strain was coded GV10. The strain was maintained on Schaedler Agar with Vitamin K1 and 5\% Sheep Blood (BD Benelux, Belgium) at $37^{\circ} \mathrm{C}$ under an anaerobic atmosphere.

For biofilm generation, GV10 was resuspended in "Schaedler broth + Vit K3" (BioMerieux Benelux, Belgium) to a $1 \mathrm{McF}$ density, and $100 \mu \mathrm{l}$ of the suspension was added to each well of a 96-well plate. The biofilm was left to form over $24 \mathrm{~h}$ at $37^{\circ} \mathrm{C}$ under an anaerobic atmosphere. The broth was then replaced with fresh media containing the lysozymes at $100,000 \mathrm{U} / \mathrm{ml}$. The plates were then incubated for $24 \mathrm{~h}$ in the presence of each lysozyme at $37^{\circ} \mathrm{C}$ under anaerobic conditions.
Biofilm quantitation was performed by crystal violet staining, as follows. The supernatant of the wells was discarded. Then, $100 \mu \mathrm{l}$ of methanol was added to each well for $15 \mathrm{~min}$ to fix the biofilm, removed, and the biofilm was left to dry at room temperature for 15 min. Then, $100 \mu \mathrm{l}$ of crystal violet $0.1 \%$ was added to the biofilms for $15 \mathrm{~min}$, and wells were rinsed twice with $100 \mu \mathrm{l}$ of deionized water. The crystal violet incorporated inside the biofilms was dissolved using $100 \mu \mathrm{l}$ of acetic acid $33 \%$ and quantitated by optical density determination at $595 \mathrm{~nm}$ using an Epoch microplate spectrophotometer (BioTek Instruments, Winooski, VT, USA).

The bactericidal assay was performed by colony forming unit (CFU) numeration, as follows. Biofilms were generated as described above. The supernatant of the culture wells was discarded. Biofilms were delicately washed with $100 \mu \mathrm{l}$ of fresh media to remove non-adherent bacteria. Each biofilm was then mechanically disrupted in $200 \mu \mathrm{l}$ of fresh media, then spread on $\mathrm{SCH}$ agar and left to grow for $48 \mathrm{~h}$ at $37^{\circ} \mathrm{C}$ under an anaerobic atmosphere before CFU numeration.

\section{Analysis of the lysozymes by SDS-PAGE}

Each of the four lysozymes was prepared in deionized water at both $300,000 \mathrm{U} / \mathrm{ml}$ and $30,000 \mathrm{U} / \mathrm{ml}$ and added to $1 \mathrm{vol}$ of Laemmli Sample buffer 2x (Bio-Rad, Belgium). The samples and molecular ladder (BioRad Precision Plus Protein Unstained Standards, BioRad, Belgium) were heated for $5 \mathrm{~min}$ at $100^{\circ} \mathrm{C}$ and loaded $(20 \mu \mathrm{l} /$ well) on $15 \%$ polyacrylamide gels, then subject to a sodium dodecyl sulfate-polyacrylamide gel electrophoresis in running buffer (Tris $0.05 \mathrm{M}$, glycine $0.38 \mathrm{M}$, sodium dodecyl sulfate $0.1 \%$, $\mathrm{pH}$ 8.3). The proteins were stained with Coomassie blue before observation.

\section{Statistical tests}

Statistical analyses were performed on results from toxicity tests and biofilm quantitation assays using respectively 2-way ANOVA followed by Bonferroni's post-hoc test, and 1-way ANOVA followed by Bonferroni's post-hoc test.

\section{RESULTS}

\section{Toxicity test on eukaryotic cells (MTS assay)}

Prior to assessing the anti-biofilm and bactericidal properties of the four lysozymes targeted in this study, we first tested their potential toxicity on the vk2/E6E7 cell line, as a model for the vaginal epithelium.

A maximal concentration of $100,000 \mathrm{U} / \mathrm{ml}$ was selected based on the literature (Sudagidan and Yemenicioglu, 2012).

Results confirmed that none of the lysozymes significantly reduced cell viability, even at the highest tested concentration (Figure 1). Therefore, we chose to use the lysozyme preparations at $100,000 \mathrm{U} / \mathrm{ml}$ on biofilms.

\section{Biofilm quantitation (CV assay)}

The anti-biofilm activity of each of the lysozymes was assessed on $24 \mathrm{~h}$ biofilms of the GV10 strain of 

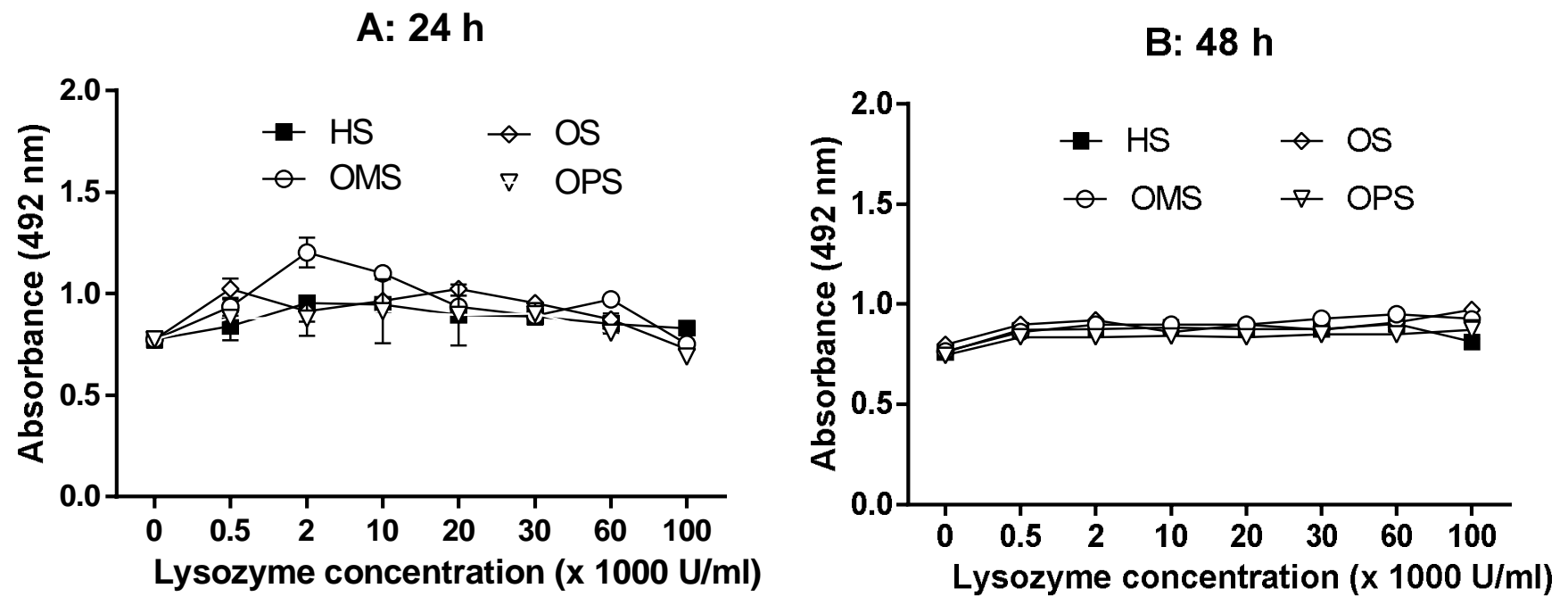

\section{C: 7 days}

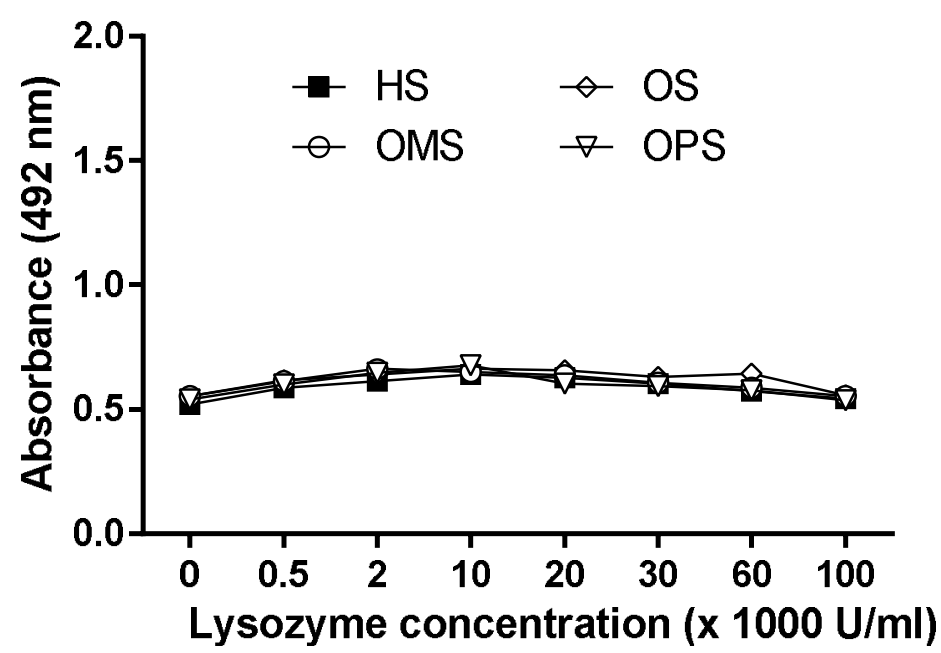

Figure 1. Cellular viability assessed by MTS assay after vk2/E6E7 cells were incubated for $24 \mathrm{~h}(\mathrm{~A}), 48 \mathrm{~h}(\mathrm{~B})$, or 7 days (C) in the presence of dilutions of each of the four tested lysozymes. HS: recombinant human lysozyme; OS, OMS, and OPS: egg white lysozymes; $\mathrm{n}=3$.

G. vaginalis. The lysozymes were added to the biofilms, which were then incubated for $24 \mathrm{~h}$, and the remaining biofilms were quantitated after treatment using a crystal violet assay. The results (Figure 2) show that each lysozyme was able to greatly reduce the amount of residual biofilm, but this effect was significantly $(p<0.01)$ stronger with the recombinant human lysozyme than with the egg white lysozymes, for which all three show almost identical values.

\section{Lysozyme bactericidal activity (CFU numeration)}

The bactericidal activity of each of the lysozymes was assessed, as for the biofilm quantitation assay, on $24 \mathrm{~h}$ biofilms of the GV10 strain of $G$. vaginalis. The lysozymes were added to the biofilms for $24 \mathrm{~h}$, then the residual bacteria of the remaining biofilms were harvested and grown on agar plates for CFU numeration. The results (Figure 3 ) show that, as for biofilm quantitation, each lysozyme was able to strongly reduce the amount of viable bacteria. In contrast to biofilm quantitation, this reduction was greater with the egg white lysozymes than with the recombinant human lysozyme.

It is worth noting that, prior to CFU numeration, biofilm disruption during the biofilm resuspension step was much easier after HS treatment of the biofilm. No such impact was observed after any of the egg white lysozyme treatments, which showed no difference from the control condition without lysozyme for that parameter. 


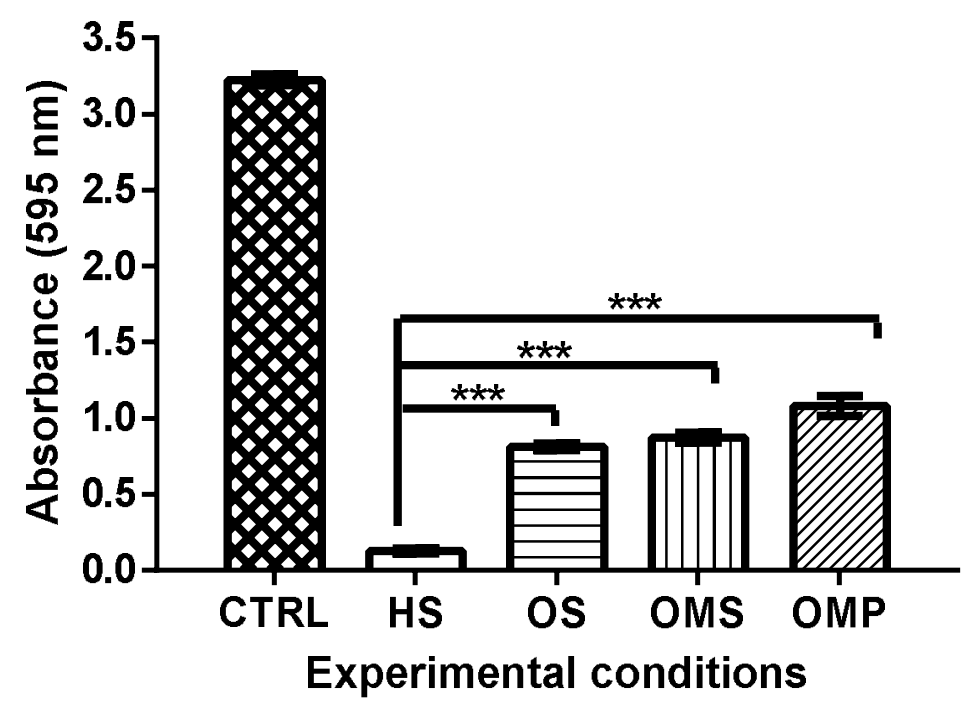

Figure 2. Biofilm quantitation by crystal violet assay. A $24 \mathrm{~h}$ biofilm is exposed to each lysozyme at $100,000 \mathrm{U} / \mathrm{ml}$ for $24 \mathrm{~h}$ then quantitated. HS: recombinant human lysozyme; OS, OMS, and OPS: egg white lysozymes; $n=4$.

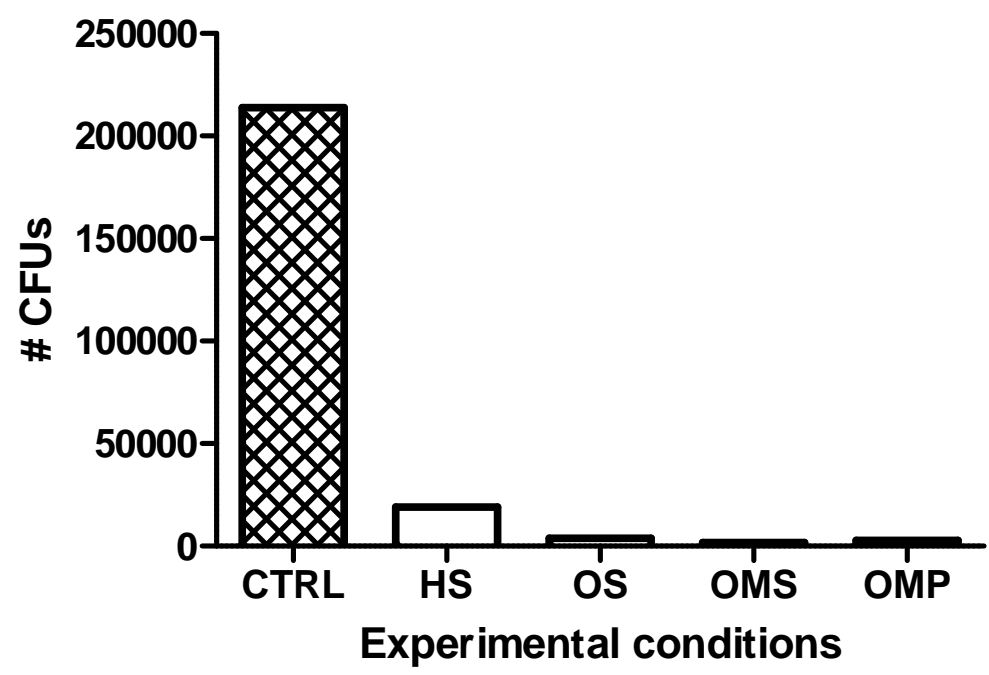

Figure 3. CFU numeration of biofilm bacteria. A $24 \mathrm{~h}$ biofilm is exposed to each lysozyme at $100,000 \mathrm{U} / \mathrm{ml}$ for $24 \mathrm{~h}$, then viable bacteria are numerated as CFUs after $48 \mathrm{~h}$ growth on agar plates. HS: recombinant human lysozyme; OS, OMS, and OPS: egg white lysozymes.

\section{Analysis of the lysozyme preparations}

The difference in results between lysozymes could be influenced by a loss of activity due to possible degradation of the lysozymes in the preparations. Therefore, we analyzed and compared the four commercial lysozymes on SDS-PAGE. After coloration of the proteins (Figure 4), we first observed that the main band was of the expected size of $14 \mathrm{kD}$ for each lysozyme. We also observed that the amount of $14 \mathrm{kD}$ protein was much higher for the same activity for OMS and OMP lysozymes. The bands for the OS and HS lysozymes were similar, if slightly more intense for OS than for HS. Smaller molecular weight bands were present at low intensity for each lysozyme, and were more visible when the $14 \mathrm{kD}$ band was more intense. These smaller bands could be degraded forms of lysozymes, but their intensities are negligible when 


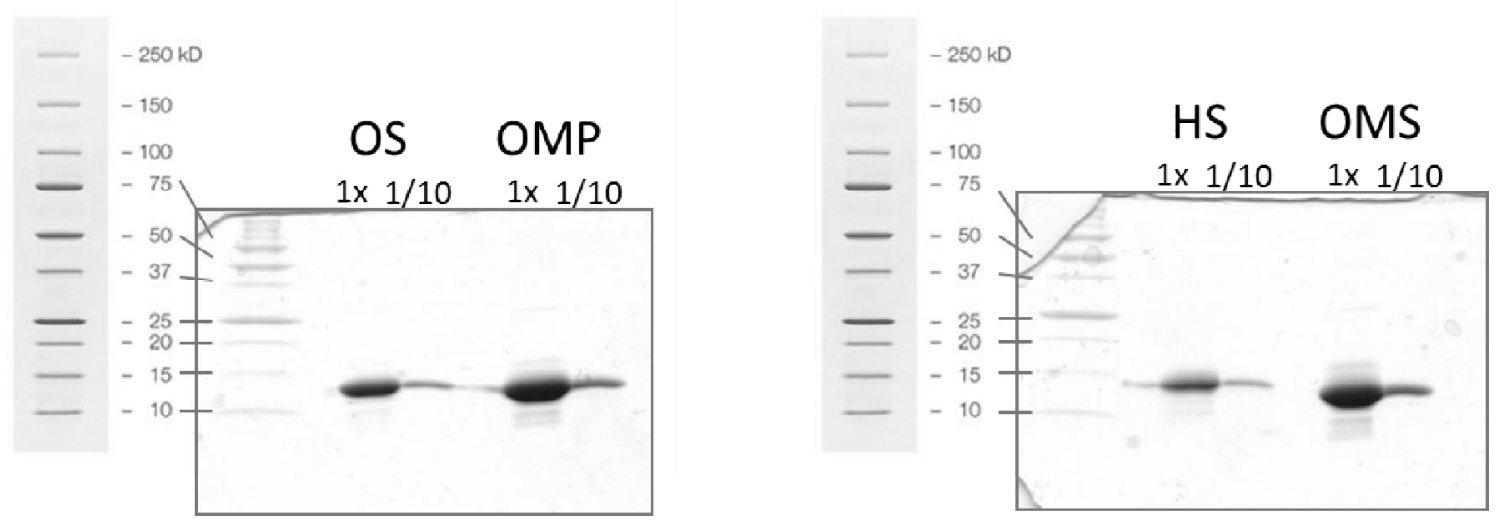

Figure 4. SDS-PAGE of $3,000 \cup(1 \mathrm{X})$ and $300 \cup(1 / 10)$ of each lysozyme. HS: recombinant human lysozyme; OS, OMS, and OPS: egg white lysozymes.

compared to the major $14 \mathrm{kD}$ bands.

\section{DISCUSSION}

Lysozymes are not expected to be toxic for human use. As an example, egg lysozyme is a common food additive used as a preservative (E1105). Egg white lysozyme is interesting for the food-processing industry due to its low cost, high yield, and anti-bacterial properties. In another work (Thellin et al., 2016), we observed that recombinant human lysozyme was able to lyse biofilms produced by various vaginal bacteria. We decided to test the ability of egg white lysozymes, alongside recombinant human lysozyme, to target a biofilm produced by $G$. vaginalis, the most frequently encountered pathological bacteria in cases of vaginosis. Three commercially-available egg white lysozymes from various sources were selected, along with previously tested recombinant human lysozyme. Our first goal was to confirm via an MTSbased assay the absence of toxicity of these lysozymes on vaginal epithelial cells at doses that produce antibiofilm activities (Thellin et al., 2016). As expected, we observed no detectable cytotoxic effect on the vk2-E6E7 epithelial cell line from each of the four lysozymes at any of the tested concentrations. However, while the lysozyme preparations did not exert cytotoxic effects on isolated vaginal epithelial cells, in vivo intravaginal administration of egg white lysozyme can generate inflammatory reactions (Pichler and Campi, 1992) against the egg lysozyme and/or other egg proteins. Egg lysozyme as food additive can also be unsuitable for consumption by persons who are allergic to eggs, accounting for 10 to $20 \%$ of egg allergy (Aabin et al., 1996). Inversely, human lysozyme is not expected to trigger allergic reactions. The recombinant human lysozyme tested here has the same amino acid sequence as human lysozyme. It is therefore supposed that recombinant human lysozyme, contrary to egg white lysozyme, should not trigger an immune reaction.
When testing the ability of the lysozymes to macroscopically degrade the $G$. vaginalis biofilm, the recombinant human lysozyme was found to be more effective than egg white lysozyme. On the other hand, the recombinant human lysozyme bactericidal effect on biofilm bacteria was unexpectedly lower than that of egg white lysozyme. The recombinant human lysozyme clearly has a higher anti-biofilm effect/bactericidal effect ratio than the egg lysozymes. This cannot be explained by a simple difference in the quality of the lysozyme preparations. The SDS-PAGE results showed that there is no significant protein degradation in these four lysozyme preparations, suggesting that observed effects were effectively due to the lysozymes.

While lysozymes from both species can simultaneously target the biofilm and the bacteria, the recombinant human lysozyme seems to be more efficient in degrading G. vaginalis biofilm, while egg white lysozymes had a higher bactericidal effect. This suggests that human and egg lysozymes possess different activities and act on different targets, instead of one being more efficient than the other. Several hypotheses can be proposed to explain such results. Firstly, lysozyme inhibitors can be present in bacterial cell wall substrates (Nakimbugwe et al., 2006). Such inhibitors have different effects on different lysozymes, meaning that lysozyme inhibitors mainly active on human lysozyme and concentrated in the bacterial cell walls could explain our results. A second hypothesis is that lysozymes could act on Gram positive bacteria through other ways than via its enzymatic activity on peptidoglycan, notably through their cationic properties (Masschalck and Michiels, 2003). G. vaginalis is a Gram variable bacteria but its cell wall structure is close to Gram positive bacteria (Catlin, 1992), suggesting that such lysozyme cationic properties could hypothetically also act on $G$. vaginalis. A third hypothesis can be also proposed. Peptidoglycan is often considered to be the only target of lysozyme. But it has been known for decades that chitin can also be hydrolyzed by lysozyme (Pangburn et al., 1982). It is therefore possible 
that lysozymes could also target one or several molecules other than peptidoglycan in $G$. vaginalis biofilms. It could also be possible that part of the biofilm degradation is due to a direct action of the lysozymes on the biofilm matrix components, and not solely a secondary consequence of the lysis of bacteria, involving lytic factors such as those described by Lewis (2000).

The recombinant human lysozyme is therefore clearly preferable to egg white lysozyme when considering antibiofilm activity. While the egg white lysozyme seems to be more efficient than recombinant human lysozyme as a bactericidal agent, it is still far less potent than antibiotics such as clindamycin or metronidazole, widely used to treat vaginoses in vivo. Therefore the best combination of anti-biofilm and bactericidal agents against vaginal biofilms produced by $G$. vaginalis, the bacteria most often encountered in vaginosis cases, would be a combination of recombinant human lysozyme and antibiotic, with the condition that this lysozyme does not trigger an immune reaction in vivo.

\section{Conclusion}

Considering first the potential absence of allergic or inflammatory reactions to recombinant human lysozyme; secondly its greater efficacy in biofilm degradation, allowing a better penetration and availability of coadministered antibiotics; and thirdly the potential bactericidal effect of lysozyme/antibiotic combinations, recombinant human lysozyme is a better choice than egg white lysozyme as an anti-biofilm co-treatment for vaginal antibiotic treatment against $G$. vaginalis infection.

\section{ACKNOWLEDGEMENT}

This work was financially supported by the Région Wallonne (Belgium), contract RW 816770, which is gratefully acknowledged.

\section{REFERENCES}

Aabin B, Poulsen LK, Ebbehøj K, Nørgaard A, Frøkiaer H, BindslevJensen $C$, Barkholt $V$, 1996. Identification of IgE-binding egg white proteins: comparison of results obtained by different methods. Int Arch Allergy Immunol, 109(1): 50-57.

Bradshaw CS, Morton AN, Hocking J, Garland SM, Morris MB, Moss LM, Horvath LB, Kuzevska I, Fairley CK, 2006. High recurrence rates of bacterial vaginosis over the course of 12 months after oral metronidazole therapy and factors associated with recurrence. $J$ Infect Dis, 193(11): 1478-1486.

Catlin BW, 1992. Gardnerella vaginalis: characteristics, clinical considerations, and controversies. Clin Microbiol Rev, 5(3): 213-237.

Fichorova RN, Rheinwald JG, Anderson DJ, 1997. Generation of papillomavirus-immortalized cell lines from normal human ectocervical, endocervical, and vaginal epithelium that maintain expression of tissue-specific differentiation proteins. Biol Reprod, 57(4): 847-855.
Fux CA, Quigley M, Worel AM, Post C, Zimmerli S, Ehrlich G, Veeh RH, 2006. Biofilm-related infections of cerebrospinal fluid shunts. Clin Microbiol Infect, 12(4): 331-337.

Gilbert P, Maira-Litran T, McBain AJ, Rickard AH, Whyte FW, 2002. The physiology and collective recalcitrance of microbial biofilm communities. Adv Microb Physiol, 46: 202-256.

Hay $P$, 2017. Bacterial vaginosis. F1000Res. 6: 1761.

Hillier SL, 1993. Diagnostic microbiology of bacterial vaginosis. Am J Obstet Gynecol, 169(2 Pt 2): 455-459.

Kenyon C, Colebunders R, Crucitti T, 2013. The global epidemiology of bacterial vaginosis: a systematic review. Am J Obstet Gynecol, 209(6): 505-523.

Lewis K, 2000. Programmed death in bacteria. Microbiol Mol Biol Rev, 64(3): 503-514.

Livengood $\mathrm{CH}, 2009$ Bacterial vaginosis: an overview for 2009. Rev Obstet Gynecol, 2(1): 28-37.

Masschalck B, Michiels CW, 2003. Antimicrobial properties of lysozyme in relation to foodborne vegetative bacteria. Crit Rev Microbiol, 29(3): 191-214.

Muzny CA, Schwebke JR, 2016. Pathogenesis of bacterial vaginosis: Discussion of current hypotheses. J Infect Dis, 214 Suppl 1: S1-5.

Nakimbugwe D, Masschalck B, Deckers D, Callewaert L, Aertsen A, Michiels CW, 2006. Cell wall substrate specificity of six different lysozymes and lysozyme inhibitory activity of bacterial extracts. FEMS Microbiol Lett, 259(1): 41-46.

Nichols WW, Dorrington SM, Slack MP, Walmsley HL, 1988. Inhibition of tobramycin diffusion by binding to alginate. Antimicrob Agents Chemother, 32(4): 518-523.

Pangburn SH, Trescony PV, Heller J, 1982. Lysozyme degradation of partially deacetylated chitin, its films and hydrogels. Biomaterials, 3(2): 105-108.

Pichler WJ, Campi P, 1992. Allergy to lysozyme/egg white-containing vaginal suppositories. Ann Allergy, 69(6): 521-525.

Reid G, 2018. Is bacterial vaginosis a disease? Appl Microbiol Biotechnol, 102(2): 553-558.

Schwebke JR, Muzny CA, Josey WE, 2014. Role of Gardnerella vaginalis in the pathogenesis of bacterial vaginosis: A conceptual model. J Infect Dis, 210(3): 338-343.

Sobel JD, Ferris D, Schwebke J, Nyirjesy P, Wiesenfeld HC, Peipert J, Soper D, Ohmit SE, Hillier SL, 2006. Suppressive antibacterial therapy with $0.75 \%$ metronidazole vaginal gel to prevent recurrent bacterial vaginosis. Am J Obstet Gynecol, 194(5): 1283-1289.

Sudagidan M, Yemenicioğlu A, 2012. Effects of nisin and lysozyme on growth inhibition and biofilm formation capacity of Staphylococcus aureus strains isolated from raw milk and cheese samples. J Food Prot, 75(9): 1627-1633.

Thellin O, Zorzi W, Zorzi D, Delvenne P, Heinen E, ElMoualij B, Quatresooz P, 2016. Lysozyme as a cotreatment during antibiotics use against vaginal infections: An in vitro study on Gardnerella vaginalis biofilm models. Int Microbiol, 19(2):101-107.
Citation: Thellin O, Zorzi D, Melin P, Delvenne P, Heinen E, Zorzi W, El Moualij B, Quatresooz P, 2018. Hen egg white lysozyme is less active against Gardnerella vaginalis biofilm than human lysozyme. Microbiol Res Int, 6(1): 1-6. 